\title{
Analysis of vascular-associated factors and the prognosis of poorly differentiated hypopharyngeal carcinoma
}

\author{
WEI GUO*, GAOFEI YIN* ${ }^{*}$, HONGFEI LIU, HANYUAN DUAN and ZHIGANG HUANG \\ Department of Otolaryngology Head and Neck Surgery, Beijing Tongren Hospital, \\ Capital Medical University, Beijing 100730, P.R. China
}

Received February 5, 2020; Accepted July 8, 2020

DOI: $10.3892 / \mathrm{ol} .2020 .12134$

\begin{abstract}
The aim of the present study was to analyze the characteristics of angiogenic factors in patients with hypopharyngeal cancer, and to study the effects of these factors on induction chemotherapy, patient prognosis and survival. Data from 60 eligible patients with hypopharyngeal cancer that were treated between January 2012 and December 2016 were collected retrospectively. The differential expression of angiogenic factors in tumor and peritumoral tissues was analyzed retrospectively to assess the association between five differentially expressed genes, including interleukin (IL)-1 $\beta$, transforming growth factor (TGF)- $\beta$, matrix metalloproteinase-9 (MMP-9), angiopoietin-2 and interferon-inducible T-cell $\alpha$ chemoattractant, and clinicopathological characteristics in different types of chemotherapy-associated blood vessels within samples of poorly differentiated hypopharyngeal cancer. The $\chi^{2}$ test or t-test was used to compare the frequency data, the Kaplan-Meier method was used for survival analysis and the log-rank test was used to compare the Kaplan-Meier curves. $\mathrm{P}<0.05$ was considered to indicate a statistically significant difference. The results of the present study demonstrated that there was a significant difference in the expression levels of vascular-associated factors between hypopharyngeal carcinoma and peritumoral tissues. Additionally, the results revealed a significant difference in the overall survival and prognosis of patients with a decreased vascular classification compared with patients with an unchanged vascular classification, which was assessed using narrowband imaging (NBI) following induction chemotherapy $(\mathrm{P}<0.05)$. The results of single factor analysis indicated that IL- $1 \beta$, TGF- $\beta$ and MMP-9 were associated with decreased blood vessel classification
\end{abstract}

Correspondence to: Professor Zhigang Huang, Department of Otolaryngology Head and Neck Surgery, Beijing Tongren Hospital, Capital Medical University, 1 Dongjiaomin Lane, Dongcheng, Beijing 100730, P.R. China

E-mail: huangzhigang1963@163.com

*Contributed equally.

Key words: hypopharyngeal carcinoma, angiogenic, chemotherapy
$(\mathrm{P}<0.05)$. In conclusion, IL-1 $\beta$, TGF- $\beta$ and MMP-9 may be used as predictors of the effect of induction chemotherapy on poorly differentiated hypopharyngeal cancer. Therefore, when patients with advanced hypopharyngeal cancer undergo chemotherapy, NBI vascular examination and screening for associated vascular factors should be performed before and after chemotherapy. Alterations in vascular classification, assessed using NBI, and abnormal expression of vascular factors may also be used as reference factors for prognosis.

\section{Introduction}

Hypopharyngeal cancer accounted for $3.0-5.0 \%$ of head and neck cancer cases worldwide in 2009; however, it has one of the poorest prognoses among all types of head and neck squamous cell carcinoma (1). In recent years, although numerous studies have been performed, and advances in comprehensive treatment have been made that have increased the organ preservation rate and local control rate, the 5-year survival rate of patients with hypopharyngeal cancer has not improved significantly; 30-40\% compared with patients exhibiting the same stage of laryngeal cancer $(2,3)$. This demonstrates that there is a considerable difference in survival rates between these two types of cancer.

A previous study has demonstrated that the type of treatment and degree of differentiation of head and neck squamous cell carcinoma can have a significant impact on patient prognosis (4). The rate of cervical lymph node metastasis in poorly differentiated hypopharyngeal carcinoma was significantly higher than that in the highly differentiated type, and the survival rate in poorly differentiated hypopharyngeal carcinoma was significantly lower than that in the highly differentiated type (5). Due to the location of hypopharyngeal cancer being well-concealed, a surgical procedure is not the best option for the majority of patients. According to the National Comprehensive Cancer Network clinical guidelines for head and neck cancer (6), induction chemotherapy should be the first line of treatment for patients with advanced hypopharyngeal cancer, and subsequent treatment can be determined according to the results of the induction chemotherapy. In a previous study (7), it has been indicated that, before and after induction chemotherapy, the change in vascular classification, as determined using narrow-band imaging (NBI), is associated with prediction of prognosis, and this may be 
associated with different angiogenic factors serving their respective roles in tumor angiogenesis. Additionally, a number of angiogenesis-related factors, including interleukin (IL)-1, transforming growth factor (TGF)- $\beta$ and matrix metalloproteinase-9 (MMP-9), have been demonstrated to be associated with tumor development in solid tumors $(8,9)$. For example, IL-1 is involved in tumor angiogenesis and lymphangiogenesis together with vascular endothelial growth factor (VEGF) and fibroblast growth factor (FGF) (8). Expression of MMP-9 and other angiogenesis-associated factors also serves an important role in promoting tumor angiogenesis, invasion and metastasis (9). Therefore, the present study used a microarray of angiogenesis-associated factors to screen the types of vascular factors that are differentially expressed.

In the present study, the clinical characteristics of hypopharyngeal carcinoma, the changes in blood vessel classification according to NBI and the differential expression of angiogenic factors were analyzed retrospectively to determine the role of angiogenesis factors in hypopharyngeal cancer and their predicted function in the prognosis of patients.

\section{Materials and methods}

Clinical data. Data from 60 patients with poorly differentiated hypopharyngeal cancer diagnosed according to the World Health Organization diagnosis standard (10) who were treated at Beijing Tongren Hospital Affiliated to the Capital Medical University (Beijing, China) between January 2012 and December 2016 were retrospectively collected. The patients selected for analysis were required to meet certain inclusion and exclusion criteria. The inclusion criteria were: i) Stage III-IV hypopharyngeal cancer according to the American Joint Committee on Cancer TNM stage (11); ii) primary cases; iii) age $<80$ years; and iv) first treatment was induction chemotherapy, with NBI examination before and after treatment. The exclusion criteria were: i) Other head and neck tumors, such as laryngeal cancer; ii) stage I-II hypopharyngeal cancer; iii) first treatment was not induction chemotherapy; iv) cancer recurrence and metastasis or secondary cancer; v) patients who had already received surgery for this cancer; vi) distant metastasis at admission; and vii) other serious systemic diseases, such as other advanced tumors or coronary heart disease, at admission. The present study screened all patients who met the criteria in the allotted range of 5 years to avoid bias. The present study was approved by the Ethics Committee of Beijing Tongren Hospital (Beijing, China), and patients provided written informed consent to participate in the present study.

Relevant standards of the treatment process. The diagnosis of hypopharyngeal cancer was based on the pathology of the patient at the time of admission, and the pathological diagnosis was performed by senior doctors. The chemotherapy plan was jointly formulated by the deputy chief physician of the Head and Neck Surgery and Oncology Department and the senior doctors following consultation. The chemotherapy plans included TPF $\left(130 \mathrm{mg} / \mathrm{m}^{2}\right.$ paclitaxel, D1; $30 \mathrm{mg} / \mathrm{m}^{2}$ cisplatin, D2-4; $500 \mathrm{mg} / \mathrm{m}^{2}$ 5-FU, D2-6, 21-28 day repeat, 2 cycles) and TP $\left(135 \mathrm{mg} / \mathrm{m}^{2}\right.$ paclitaxel, D1; $70 \mathrm{mg} / \mathrm{m}^{2}$ cisplatin, D2-4; 21 day repeat, 2 cycles). After induction chemotherapy treatment, the senior doctors in the imaging department used image examination and stroboscopic laryngoscopy to jointly determine the efficacy of treatment, including complete remission (CR), partial remission (PR), stable disease (SD) and progressive disease, and formulated the subsequent treatment plan. Before induction chemotherapy treatment and 2 weeks after induction chemotherapy treatment, the blood vessel classification according to NBI was determined by senior doctors at the Head and Neck Surgery and Voice Center. In the present study, an NBI electronic fiber laryngoscope (model, Otv-s190) manufactured by Olympus Corporation was used. The image system was OTV-S7PRO (Olympus Corporation) and the cold light source system was CLV-S40PRO (Olympus Corporation). The conversion between white light mode and NBI mode could be completed by pressing the down button. The method of classification was as follows: Type I (poly P), hard to see oblique branches, such as intrapapillary capillary loops (IPCL; A1-A3); type II (laryngitis), enlarged, oblique branch-like blood vessels (B1-B3); type III (simple hyperplasia and mild atypical hyperplasia), IPCL covered by white mucosa (C1-C3); type IV (mild-to-moderate atypical hyperplasia), spots clearly visible with a regular arrangement but low density (D1-D3); type V (mild-to-severe atypical hyperplasia and invasive cancer) was divided into three subtypes (type V A, type V B and type V C), type V A exhibited bloated high density spots with various shapes (E1-E3); type V B exhibited irregular twisted earthworm-like IPCL (F1-F3); type V C exhibited irregular twisted or spotted IPCL (G1-G3) on the surface of the tumor, of which $100 \%$ of type $\mathrm{V} \mathrm{B}$ and type $\mathrm{V} \mathrm{C}$ indicated invasive cancer (Fig. 1) (12). The more obvious the neovascularization, the more likely the tumor is to be malignant and the more serious the disease (12). During induction chemotherapy, the NBI blood vessel classification changed from type $\mathrm{V}$ to type I-IV or from type V B and V C to type V A, which was defined as a decrease in blood vessel classification. In this group, 30 cases exhibited a decrease in NBI blood vessel classification and 30 cases were unchanged in NBI blood vessel classification.

Human angiogenesis antibody array. The RayBio ${ }^{\circledR}$ G-Series Human Angiogenesis Antibody Array 1000 kit (RayBiotech, Inc.) was used. For tissue lysis, tumor and peritumoral tissues were collected via resection and frozen at $-80^{\circ} \mathrm{C}$ until further use. The tissues were then cut with surgical scissors into 1-3 $\mathrm{mm}^{3}$ cubes and transferred to a $2-\mathrm{ml}$ centrifuge tube. Cell lysate $(150 \mu \mathrm{l})$ was added, and the mixture was stored at a low temperature on ice and homogenized for 5-15 $\mathrm{min}$. The mixture was then centrifuged at room temperature at $7.4 \mathrm{x} \mathrm{g}$ for $10 \mathrm{~min}$ and the supernatant was removed for subsequent use.

To measure protein concentration and dilution, following cell lysis, the protein concentration of the tissue lysate was determined using a Pierce BCA protein assay kit (cat. no. 23227; Pierce; Thermo Fisher Scientific, Inc.). A total of $100 \mu 1 \mathrm{X}$ PBS as the sealing solution was added to each chip hole, and the mixture was incubated in a shaker at room temperature for $30 \mathrm{~min}$.

Subsequently, the sealing solution (PBS) was removed, and $100 \mu \mathrm{l}$ of the sample was added to each well and incubated overnight at $4^{\circ} \mathrm{C}$ (the sample was centrifuged at room 


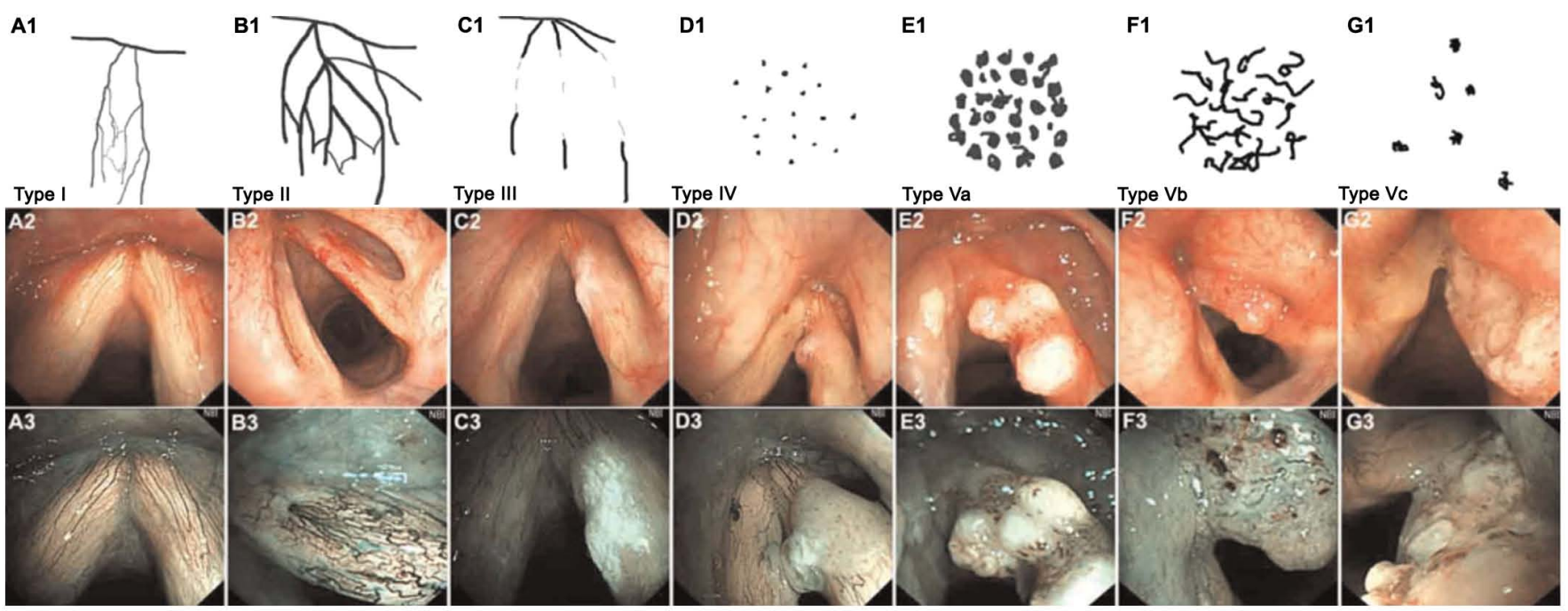

Figure 1. Blood vessel classification by narrowband imaging from Type I to Type Vc. (A1-3) Type I: Thin, oblique and arborescent vessels are interconnected and intraepithelial papillary capillary loops are almost invisible. (B1-3) Type II: Diameter of oblique and arborescent vessels is enlarged, and intraepithelial papillary capillary loops are almost invisible. (C1-3) Type III: Intraepithelial papillary capillary loops are obscured by white mucosa. (D1-3) Type IV: Intraepithelial papillary capillary loops can be recognized as small dots. (E1-3) Type Va: Intraepithelial papillary capillary loops appear as solid or hollow, with a brownish, speckled pattern and various shapes. (F1-3) Type Vb: Intraepithelial papillary capillary loops appear as irregular, tortuous, line-like shapes. (G1-3) Type Vc: Intraepithelial papillary capillary loops appear as brownish speckles or tortuous, line-like shapes with irregular distribution, scattered on the tumor surface (12). Panels A2-G2 were imaged using white light, while panels A3-G3 using narrowband imaging.

temperature at $7.2 \mathrm{x}$ g for $4 \mathrm{~min} ; 0.5 \mathrm{mg} / \mathrm{ml})$. A Wellwash Versa Microplate Washer (Thermo Fisher Scientific, Inc.) was used to clean the slides. A total of $70 \mu \mathrm{l}$ biotin was added to each pore and the samples were incubated at room temperature for $2 \mathrm{~h}$. Subsequently, $70 \mu \mathrm{l}$ streptavidin fluorescent agent (dilution, 1,500) was added to each pore and samples were incubated for 1-2 $\mathrm{h}$ at room temperature in the dark. A laser scanner (Axon GenePix Microarray scanner; Molecular Devices, LLC) was used to detect the signal, and a $\mathrm{Cy} 3$ channel (excitation wavelength, $532 \mathrm{~nm}$ ) was used to detect staining. Subsequently, the data of the relative expression levels were obtained by over density quantitative analysis and standardized calculation, and the Human Angiogenesis Array G1 (AAH-ANG-G1) and Human Angiogenesis Array G2 (AAH-ANG-G2) kits (RayBiotech, Inc.) were used for the data analysis according to the manufacturer's protocol.

Immunohistochemistry. A total of $1 \mathrm{~cm}^{3}$ of tissue was taken and fixed with $4 \%$ paraformaldehyde for $24 \mathrm{~h}$ at room temperature and dehydrated in different ethanol concentrations $(50,70,80$ and $95 \%$ for $2 \mathrm{~h}$ each, and $100 \%$ for $1 \mathrm{~h}$ at room temperature). Tissue samples were treated with xylene, embedded in paraffin at $52^{\circ} \mathrm{C}$ and cut into $4-\mu$ m-thick sections. After paraffin-embedded sections were dewaxed in xylene at room temperature and rehydrated in different ethanol concentrations (100, 85 and $75 \%)$ at room temperature, the tissue sections were placed in a repair box filled with EDTA antigen repair buffer ( $\mathrm{pH} 8.0)$, and then antigen was retrieved using a microwave oven. The samples were heated at boiling temperature for $9 \mathrm{~min}$, stopped for $7 \mathrm{~min}$ and then at medium heat for $7 \mathrm{~min}$. After natural cooling, the slides were placed in PBS ( $\mathrm{pH}$ 7.4) and shaken on the decolorizing shaker for 3 times ( 5 min each time). The slides were incubated with $3 \%$ hydrogen peroxide solution for $25 \mathrm{~min}$ at room temperature. The slides were placed in PBS ( $\mathrm{pH} 7.4)$ and washed 3 times on a decolorizing shaker for 5 min each time. Slides were blocked with $3 \%$ BSA added into the histochemical circle to cover the tissue homogeneously for $30 \mathrm{~min}$ at room temperature. After shaking off the blocking solution gently, the slides were incubated with primary antibodies (all diluted 1:200 in PBS) against IL-1 (cat. no. ab2105; Abcam), TGF- $\beta$ (cat. no. ab92486; Abcam), MMP-9 (cat. no. ab58803; Abcam), angiopoietin-2 (Ang-2; cat. no. ab56301; Abcam) and interferon-inducible T-cell $\alpha$ chemoattractant (I-TAC; cat. no. 70R-IR053; Fitzgerald Industries) overnight at $4^{\circ} \mathrm{C}$. The slides were washed with PBS ( $\mathrm{pH} 7.4)$ and were then covered with HRP-labeled goat anti-rabbit (1:200; cat. no. GB23303; Wuhan Servicebio Technology Co., Ltd.) or goat anti-mouse (1:200; cat. no. GB23301; Wuhan Servicebio Technology Co., Ltd.) secondary antibodies and incubated at room temperature for $50 \mathrm{~min}$. PBS replaced the primary antibody as the negative control, and the company (Abcam) provided a positive reference to use as the positive control. Each step was performed according to the requirements of the 3,3'-diaminobenzidine staining kit (cat. no. D7051; Beijing Solarbio Science \& Technology, Co., Ltd.). Positive expression of the yellow-brown reaction product was indicated in the nucleus or the cytoplasm. Cells in a total of five fields were randomly counted manually using a high power light microscope (magnification, x200). In total, 100 tumor cells were counted in each field. A number of positively stained cells $>10 \%$ was considered to indicate a positive result. For the fixation of samples, the present study used a fixed time of $24 \mathrm{~h}$. If the fixation time is too long, the antigenic determinants of cells will be covered and lost, due to the cross-linking between formaldehyde and tissue protein, and this will affect their expression activity (13).

Follow-up. Patient follow-up was a combination of regular outpatient reviews and telephone follow-up appointments. Up to the follow-up time, no patient was lost, 46 patients survived 
Table I. Expression levels of tumor/peritumoral differential factors in 60 patients.

\begin{tabular}{lcccccc}
\hline Factor & Tumor (median) & Peri-tumor (median) & Fold change & T & P-value & 95\% CI \\
\hline MMP-9 & $6,550.40$ & 855.55 & 6.30 & 17.72 & $<0.01$ & $5,658.98-7,082.86$ \\
TGF- $\beta$ & $1,609.00$ & 38.95 & 41.0 & 37.71 & $<0.01$ & $1,411.900-1,568.39$ \\
IL-1 $\beta$ & $48,499.55$ & 745.00 & 64.00 & 27.89 & $<0.01$ & $44,922.21-51,790.29$ \\
Ang-2 & $19,049.50$ & $5,490.00$ & 3.30 & 37.96 & $<0.01$ & $13,145.55-14,592.52$ \\
I-TAC & $3,510.50$ & 360.50 & 10.00 & 232.69 & $<0.01$ & $28,938.80-3,317.82$ \\
\hline
\end{tabular}

Ang-2, angiopoietin-2; I-TAC, interferon-inducible T-cell $\alpha$ chemoattractant; IL-1 $\beta$, interleukin-1 $\beta$; MMP-9, matrix metalloproteinase-9; TGF- $\beta$, transforming growth factor- $\beta$.

and 14 died. The date for follow-up to death, or end of the study period, was October 2019.

Statistical analysis. SPSS software version 22.0 (IBM Corp.) was used for the statistical analysis. The $\chi^{2}$ test or unpaired Student's t-test were used for categorical or continuous data, respectively. and Cox regression analysis were used for single factor analysis of clinical indicators. The Kaplan-Meier method and the log-rank test were used to analyze the difference in Kaplan-Meier curves between groups. The data are presented as the averages. $\mathrm{P}<0.05$ was considered to indicate a statistically significant difference.

\section{Results}

Differential expression of angiogenic antibody CHIP in tumors and peritumoral tissue. The log ratio of differentially expressed genes in tumor tissue and para-cancerous tissue from each patient was determined. The genes included epithelial-derived neutrophil-activating protein 78, IL-1 $\beta$, phosphatidylinositol glycan anchor biosynthesis class $\mathrm{F}$, urokinase-type plasminogen activator, interferon-inducible T-cell $\alpha$ chemoattractant (I-TAC), VEGF, MMP-1, monocyte chemoattractant protein 3, VEGF-D, inflammatory cytokine I-309, IL-4, LEPTIN, TIMP metallopeptidase inhibitor 1, insulin-like growth factor 1, angiopoietin (Ang-2), epidermal growth factor and MMP-9. A total of five differentially expressed genes, including IL-1 $\beta$, TGF- $\beta$, MMP-9, Ang-2 and I-TAC, were selected using the Angiogenesis Antibody Array in the 60 patients (Table I).

Immunohistochemistry results. The expression levels of IL-1 $\beta$, TGF- $\beta$, MMP-9, Ang- 2 and I-TAC in hypopharyngeal carcinoma were determined by immunohistochemistry (Fig. 2). The immunohistochemical results of each vascular factor were observed under a microscope.

Analysis of NBI, vascular factors and survival. The average age of the 60 patients was 61.5 years and the median follow-up time was 35 months (Table II). In October 2019, 46 patients were still alive and 14 had died. A total of 38 patients had a history of smoking, 40 had a history of drinking and all 60 patients were male. According to the American Joint Committee on Cancer TNM stage (11), 20 patients had stage III hypopharyngeal cancer and 40 patients had stage IV hypopharyngeal cancer. The subsites of tumor location were: Posterior area of cricoid cartilage $(n=2)$; pyriform sinus $(n=6)$; posterior wall of laryngopharynx $(n=0)$; and multiple subsites $(\mathrm{n}=52)$. After induction chemotherapy, 8 patients had CR, 44 had PR and 8 patients had SD. Until October 2019, a total of 8 patients exhibited local recurrence, 36 exhibited lymph node metastasis and 20 exhibited distant metastasis (Table III).

The two groups with decreased or unchanged NBI vascular classification were analyzed for differences in clinicopathological characteristics, including age, sex, history of tobacco and alcohol use, disease stage, induction chemotherapy plan, and response to induction chemotherapy. A $\chi^{2}$ or t-test was used for statistical analysis, and the results are presented in Table II. The only statistically significant difference between the two groups was the change in NBI vascular classification before and after induction chemotherapy $(\mathrm{P}<0.001)$. A t-test was performed to determine the differences in the expression levels of five vascular factors between the two groups, and the results indicated that the expression levels of MMP-9, IL-1 $\beta$ and TGF- $\beta$ were significantly different between the two groups $(\mathrm{P}<0.001)$. The expression levels were higher in the group with unchanged NBI vascular type (Table IV).

Single factor Kaplan-Meier analysis was performed for factors that may affect the survival rate of the 60 patients, including age, sex, smoking and alcohol history, disease stage, induction chemotherapy plan, response to induction chemotherapy, treatment plan after chemotherapy, local recurrence, lymph node metastasis, distant metastasis, and decreased/unchanged NBI blood vessel classification. The effects of the five vascular factors on the survival and prognosis of patients were analyzed. As shown in Tables III and V, the factors that may affect the prognosis of patients were TNM stage, treatment plan after induction chemotherapy, local recurrence, lymph node metastasis, distant metastasis, decreased NBI blood vessel classification and expression levels of vascular factors MMP-9, IL-1 $\beta$ and TGF- $\beta$.

Multivariate Cox regression analysis was also performed to identify potential factors associated with prognosis (Table VI). The results indicated that decreased NBI blood vessel classification and distant metastasis were factors that affected the prognosis of patients, among which distant metastasis was a risk factor. Additionally, decreased NBI vascular classification was a protective factor for prognosis. The survival curve in Fig. 3 shows the association between decreased/unchanged 


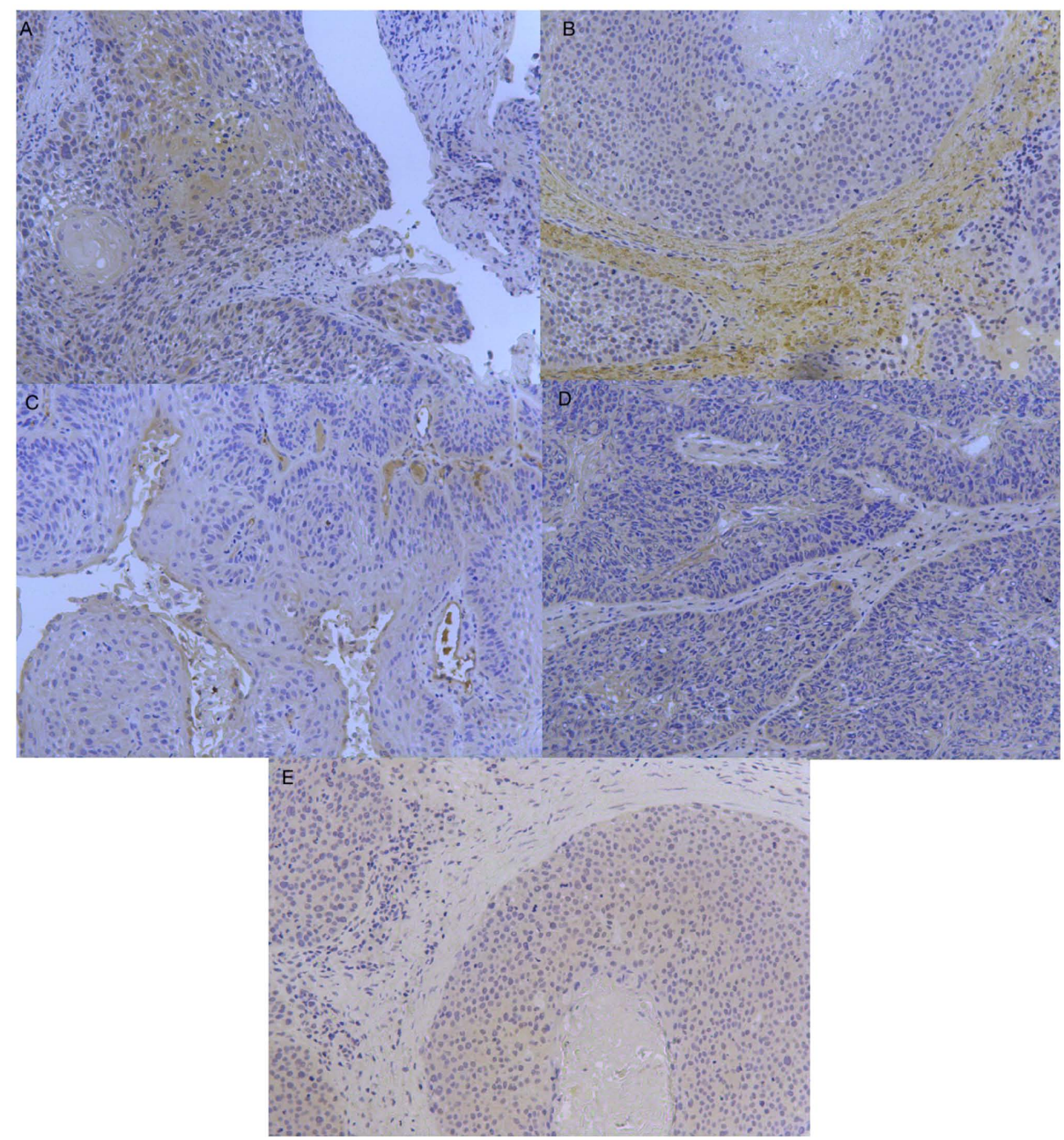

Figure 2. Representative immunohistochemical images. (A) Immunohistochemical staining of interleukin-1 $\beta$ observed under a microscope. Magnification, $\mathrm{x} 200$. (B) Immunohistochemical staining of matrix metalloproteinase-9 observed under a microscope. Magnification, x200. (C) Immunohistochemical staining of angiopoietin-2 observed under a microscope. Magnification, x200. (D) Immunohistochemical staining of interferon-inducible T-cell $\alpha$ chemoattractant observed under a microscope. Magnification, x200. (E) Immunohistochemical staining of transforming growth factor- $\beta$ observed under a microscope. Magnification, x200.

NBI blood vessel classification and overall survival rate, revealing that unchanged NBI blood vessel classification was associated with a worse overall survival rate.

\section{Discussion}

Tumor angiogenesis refers to the process of tumor cell-induced capillary growth and the establishment of tumor blood circulation, which serves an important role in tumor growth, invasion, diffusion and metastasis. This process is regulated by a variety of cytokines, among which angiogenesis factor is an important regulatory factor (14).

The abnormal secretion of angiogenic factors occurs in the early stages of tumor occurrence, assists in the formation of tumor neovascularization and promotes tumor occurrence (15). For example, Ang-2, which was investigated in the present study, is an early angiogenic factor (15). The Ang family is associated with angiogenesis, and a large number of studies have confirmed that it serves an important role in the occurrence and development of human malignant tumors $(15,16)$. Ang- 1 and Ang-2 are the most well-known members of the Ang family, and Ang- 2 belongs to the secretory proteins. In the pathological state, Ang-2 is primarily expressed in areas of inflammation, tissue damage and metastasis, and is expressed most abundantly in the neovascular network (17). In the early stages of malignant tumor formation, Ang-2 is expressed in endothelial cells when new blood vessels begin to develop, which destroys the stability of blood vessels and the original vascular network around the new tumor body, and forms the vascular co-selection area, leading to the reconstruction of microvasculature.

To the best of our knowledge, no studies have investigated Ang-2 in squamous cell carcinoma of the head and neck, but it has been indicated that high expression of Ang-2 is an early event in esophageal cancer (18). Ang-2 expression has been demonstrated to not be significantly increased in the middle or late stages of squamous cell carcinoma, to not be an independent factor for the prognosis of esophageal cancer (18) and to not be associated with the prognosis of patients with this disease. These results are consistent with the conclusions of the present study. In addition, Ang-2 has been indicated to activate infiltration-associated cytokines, including MMPs, and promote the invasion and progression of tumor cells (19). Furthermore, Ang-2 has been demonstrated to improve the responsiveness and sensitivity of tumor cells and vascular 
Table II. Summary of the association between the decreased/unchanged NBI blood vessel classification and the general situation of patients.

\begin{tabular}{|c|c|c|c|c|}
\hline Factor & $\begin{array}{l}\text { Decreased NBI blood vessel } \\
\text { classification }(n=30)\end{array}$ & $\begin{array}{l}\text { Unchanged NBI blood vessel } \\
\text { classification }(n=30)\end{array}$ & $\chi^{2} / \mathrm{T}$ & P-value \\
\hline Mean age $\pm S D$, years & $60.47 \pm 1.558$ & $62.53 \pm 1.254$ & 1.003 & 0.087 \\
\hline Median follow up, months & 35 & 35 & - & - \\
\hline Sex & & & - & - \\
\hline Male & 30 & 30 & & \\
\hline Female & 0 & 0 & & \\
\hline Smoking $^{\mathrm{a}}$ & & & 0.287 & 0.592 \\
\hline Yes & 20 & 18 & & \\
\hline No & 10 & 12 & & \\
\hline Drinking $^{\mathrm{b}}$ & & & 1.200 & 0.273 \\
\hline Yes & 22 & 18 & & \\
\hline No & 8 & 12 & & \\
\hline TNM stage & & & 5.293 & 0.507 \\
\hline Stage III & 10 & 10 & & \\
\hline $\mathrm{T} 2 \mathrm{~N} 1 \mathrm{M} 0$ & 0 & 2 & & \\
\hline T3N0M0 & 9 & 7 & & \\
\hline T3N1M0 & 1 & 1 & & \\
\hline Stage IV & 20 & 20 & & \\
\hline $\mathrm{T} 2 \mathrm{~N} 2 \mathrm{M} 0$ & 6 & 2 & & \\
\hline $\mathrm{T} 3 \mathrm{~N} 2 \mathrm{M} 0$ & 11 & 12 & & \\
\hline T4NOM0 & 2 & 4 & & \\
\hline T4N1M0 & 1 & 2 & & \\
\hline Chemotherapy & & & 1.667 & 0.197 \\
\hline $\mathrm{TPF}$ & 22 & 26 & & \\
\hline $\mathrm{TP}$ & 8 & 4 & & \\
\hline Chemotherapy response & & & 14.100 & $<0.001$ \\
\hline CR & 8 & 0 & & \\
\hline PR & 22 & 22 & & \\
\hline SD & 0 & 8 & & \\
\hline PD & 0 & 0 & & \\
\hline Subsite & & & -0.652 & 0.517 \\
\hline Posterior area of cricoid cartilage & 1 & 1 & & \\
\hline Pyriform sinus & 4 & 2 & & \\
\hline Posterior wall of laryngopharynx & 0 & 0 & & \\
\hline Multiple subsites & 25 & 27 & & \\
\hline
\end{tabular}

a'Smoking, Yes' were those subjects who had smoked $>100$ cigarettes in their lifetime, whereas 'smoking, No' had smoked $\leq 100$ or fewer.

'A Alcohol drinking, Yes' were those individuals who drank alcoholic beverages at least once a week for $>1$ year, and the others were 'alcohol drinking, No'. TPF, $130 \mathrm{mg} / \mathrm{m}^{2}$ paclitaxel (D1), $30 \mathrm{mg} / \mathrm{m}^{2}$ cisplatin (D2-4), $500 \mathrm{mg} / \mathrm{m}^{2}$ 5-FU (D2-6), 21-28 day repeat, 2 cycles; TP, $135 \mathrm{mg} / \mathrm{m}^{2}$ paclitaxel (D1), $70 \mathrm{mg} / \mathrm{m}^{2}$ cisplatin (D2-4), 21 day repeat, 2 cycles; CR, complete remission; PR, partial remission; SD, stable disease; PD, progressive disease; NBI, narrowband imaging.

endothelial cells to VEGF (19), and further participates in tumor angiogenesis and growth.

When a tumor reaches a certain size, the original blood vessels are not able to transport sufficient nutrients to the distant tumor $(20,21)$. The rapid growth and apoptosis rate of the tumor are lower compared with normal tissue, which has a large demand for oxygen, and can cause vasospasm and oxygen deficiency in tissues; however, the tumor can mitigate this by regulating itself and promoting angiogenesis (20-22). During hypoxia, tumor cells can adapt to the hypoxic microenvironment by expressing hypoxia inducible factor-1 (HIF-1) (23). HIF-1 can promote the high expression of TGF- $\beta 1$ mRNA and the increased secretion of TGF- $\beta 1$ protein in esophageal squamous cell carcinoma by regulating VEGF, in order to regulate 
Table III. Analysis of single factors influencing the prognosis of patients.

\begin{tabular}{|c|c|c|c|c|c|}
\hline Factor & Total, $\mathrm{n}$ & Event (death), n & $95 \% \mathrm{CI}$ & $\chi^{2} / \mathrm{T}$ & P-value \\
\hline Average age, years & 61.50 & 61.48 & $-3.743-5.793$ & 20.229 & 0.210 \\
\hline Sex & & & $39.325-48.609$ & - & - \\
\hline Male & 60 & 14 & & & \\
\hline Female & 0 & 0 & & & \\
\hline Smoking $^{\mathrm{a}}$ & & & & 3.232 & 0.072 \\
\hline Yes & 38 & 6 & $38.654-47.452$ & & \\
\hline No & 22 & 8 & $29.467-47.076$ & & \\
\hline Drinking ${ }^{\mathrm{b}}$ & & & & 0.334 & 0.563 \\
\hline Yes & 40 & 10 & $36.817-48.883$ & & \\
\hline No & 20 & 4 & $36.227-48.173$ & & \\
\hline TNM stage & & & & 20.789 & 0.002 \\
\hline Stage III & 20 & 6 & 21.299-31.544 & & \\
\hline T2N1M0 & 2 & 0 & & & \\
\hline T3N0M0 & 16 & 6 & & & \\
\hline T3N1M0 & 2 & 0 & & & \\
\hline Stage IV & 40 & 8 & $30.989-40.907$ & & \\
\hline $\mathrm{T} 2 \mathrm{~N} 2 \mathrm{M} 0$ & 8 & 0 & & & \\
\hline T3N2M0 & 23 & 2 & & & \\
\hline T4N0M0 & 6 & 4 & & & \\
\hline T4N1M0 & 3 & 2 & & & \\
\hline Chemotherapy & & & & 0.525 & 0.469 \\
\hline $\mathrm{TPF}$ & 48 & 12 & $37.569-48.431$ & & \\
\hline $\mathrm{TP}$ & 12 & 2 & $36.297-49.370$ & & \\
\hline Chemotherapy response & & & & 0.007 & 0.996 \\
\hline $\mathrm{CR}$ & 8 & 2 & $30.048-47.452$ & & \\
\hline PR & 44 & 10 & $38.034-49.329$ & & \\
\hline $\mathrm{SD}$ & 8 & 2 & $27.799-42.201$ & & \\
\hline Therapy after chemotherapy & & & & 10.107 & 0.006 \\
\hline Surgery & 38 & 8 & & & \\
\hline Radiotherapy & 10 & 6 & & & \\
\hline Surgery + radiotherapy & 12 & 0 & & & \\
\hline Local recurrence & & & & 4.547 & $<0.001$ \\
\hline Yes & 8 & 8 & $9.857-16.143$ & & \\
\hline No & 52 & 6 & $44.742-52.719$ & & \\
\hline Lymph node metastasis & & & & 8.729 & 0.003 \\
\hline Yes & 36 & 4 & $45.657-53.676$ & & \\
\hline No & 24 & 10 & $22.641-36.525$ & & \\
\hline Distant metastasis & & & & 34.071 & $<0.001$ \\
\hline Yes & 20 & 14 & & & \\
\hline No & 40 & 0 & & & \\
\hline Decreased NBI blood vessel classification & & & & 9.986 & 0.002 \\
\hline Yes & 30 & 2 & $48.231-54.836$ & & \\
\hline No & 30 & 12 & 26.054-39.546 & & \\
\hline
\end{tabular}

a'Smoking, Yes' were those subjects who had smoked $>100$ cigarettes in their lifetime, whereas 'smoking, No' had smoked $\leq 100$ or fewer. b'Alcohol drinking, Yes' were those individuals who drank alcoholic beverages at least once a week for $>1$ year, and the others were 'alcohol drinking, No'. TPF, $130 \mathrm{mg} / \mathrm{m}^{2}$ paclitaxel (D1), $30 \mathrm{mg} / \mathrm{m}^{2}$ cisplatin (D2-4), $500 \mathrm{mg} / \mathrm{m}^{2} 5-\mathrm{FU}$ (D2-6), 21-28 day repeat, $2 \mathrm{cycles}$; TP, $135 \mathrm{mg} / \mathrm{m}^{2}$ paclitaxel (D1), $70 \mathrm{mg} / \mathrm{m}^{2}$ cisplatin (D2-4), 21 day repeat, 2 cycles; CR, complete remission; PR, partial remission; SD, stable disease; NBI, narrowband imaging. 
Table IV. Association between decreased/unchanged NBI blood vessel classification and vascular factors.

\begin{tabular}{|c|c|c|c|c|c|}
\hline Vascular factor & $\begin{array}{c}\text { Decreased NBI } \\
\text { blood vessel } \\
\text { classification } \\
\text { (average) }\end{array}$ & $\begin{array}{l}\text { Unchanged NBI } \\
\text { blood vessel } \\
\text { classification } \\
\text { (average) }\end{array}$ & $\mathrm{T}$ & P-value & $95 \% \mathrm{CI}$ \\
\hline MMP-9 & 782.957 & $7,177.387$ & 12.478 & $<0.001$ & $5,368.633-7,420.228$ \\
\hline TGF- $\beta$ & 39.785 & $1,590.558$ & 29.226 & $<0.001$ & $144.558-1,656.988$ \\
\hline IL-1 $\beta$ & 804.127 & $49,095.463$ & 19.523 & $<0.001$ & $43,340.072-53,242.600$ \\
\hline Ang-2 & $6,630.833$ & $8,109.133$ & 1.179 & 0.243 & $-1,032.613-3,989.214$ \\
\hline I-TAC & 2567.676 & $2,408.063$ & -0.265 & 0.792 & $-1,363.993-1,044.768$ \\
\hline
\end{tabular}

Ang-2, angiopoietin-2; I-TAC, interferon-inducible T-cell $\alpha$ chemoattractant; IL-1 $\beta$, interleukin-1 $\beta$; MMP-9, matrix metalloproteinase-9; TGF- $\beta$, transforming growth factor- $\beta$; NBI, narrowband imaging.

Table V. Association between vascular factor expression and survival.

\begin{tabular}{|c|c|c|c|c|c|}
\hline Factor & Survival (average) & Death (average) & $\chi^{2}$ & $\mathrm{df}$ & P-value \\
\hline MMP-9 & $4,086.329$ & $4,308.548$ & 141.847 & 46 & $<0.001$ \\
\hline TGF- $\beta$ & 815.172 & 883.353 & 132.630 & 47 & $<0.001$ \\
\hline IL-1 $\beta$ & $24,949.795$ & $26,235.434$ & 146.498 & 56 & $<0.001$ \\
\hline Ang-2 & 7,969.983 & 7,974.060 & 116.868 & 58 & 0.737 \\
\hline I-TAC & $2,387.869$ & $2,399.797$ & 102.252 & 53 & 0.837 \\
\hline
\end{tabular}

Ang-2, angiopoietin-2; I-TAC, interferon-inducible T-cell $\alpha$ chemoattractant; IL-1 $\beta$, interleukin-1 $\beta$; MMP-9, matrix metalloproteinase-9; TGF- $\beta$, transforming growth factor- $\beta$.

Table VI. Multivariate Cox regression analysis.

\begin{tabular}{|c|c|c|c|c|c|c|}
\hline Variable & $\mathrm{B}$ & SE & Wald & P-value & HR & $95 \% \mathrm{CI}$ \\
\hline TNM stage & -1.457 & 1.006 & 2.097 & 0.148 & 0.233 & $0.032-1.674$ \\
\hline Decreased NBI blood vessel classification & -18.105 & 8.526 & 4.509 & 0.034 & 0.000 & $0.000-0.248$ \\
\hline Lymph node metastasis & -6.320 & 3.833 & 2.719 & 0.099 & 0.002 & $0.000-3.295$ \\
\hline Distant metastasis & 27.078 & 12.414 & 4.758 & 0.029 & 3.163 & $0.660-15.164$ \\
\hline Local recurrence & -4.363 & 3.009 & 2.102 & 0.147 & 0.013 & $0.000-4.642$ \\
\hline Therapy after chemotherapy & -7.187 & 3.884 & 3.425 & 0.064 & 0.001 & $0.000-1.530$ \\
\hline MMP-9 & 0.000 & 0.000 & 0.053 & 0.817 & 1.000 & $1.000-1.001$ \\
\hline TGF & -0.001 & 0.002 & 0.071 & 0.790 & 0.999 & $0.995-1.004$ \\
\hline IL1 & 0.000 & 0.000 & 0.134 & 0.714 & 1.000 & $1.000-1.000$ \\
\hline
\end{tabular}

IL1, interleukin-1; MMP-9, matrix metalloproteinase-9; TGF, transforming growth factor; NBI, narrowband imaging; HR, hazard ratio; CI, confidence interval.

the neovascularization of the tumor and control hypoxia (24). TGF- $\beta$ is a member of the TGF superfamily, which serves a role in the formation of tumor blood vessels, and in tumor invasion and metastasis (25).

TGF- $\beta$ has been indicated to exhibit a two-way effect on tumors, causing inhibition of cell canceration in early stage tumors and promotion of invasion and metastasis in advanced stage tumors (25). In the early stages of tumor growth, TGF- $\beta$ is primarily associated with the regulation of the cell cycle and the induction of cell apoptosis to prevent cell carcinogenesis (26). In the advanced stages of tumor growth, TGF- $\beta$ promotes tumor cell invasion and metastasis by stimulating the proliferation of the extracellular matrix, and promoting angiogenesis and immunosuppression (26). This has been demonstrated in a previous study that focused on esophageal squamous cell carcinoma. In the early stages (stage I) of esophageal cancer formation, TGF- $\beta$ expression increases due to its inhibitory effect in the early tumor, while in the late 


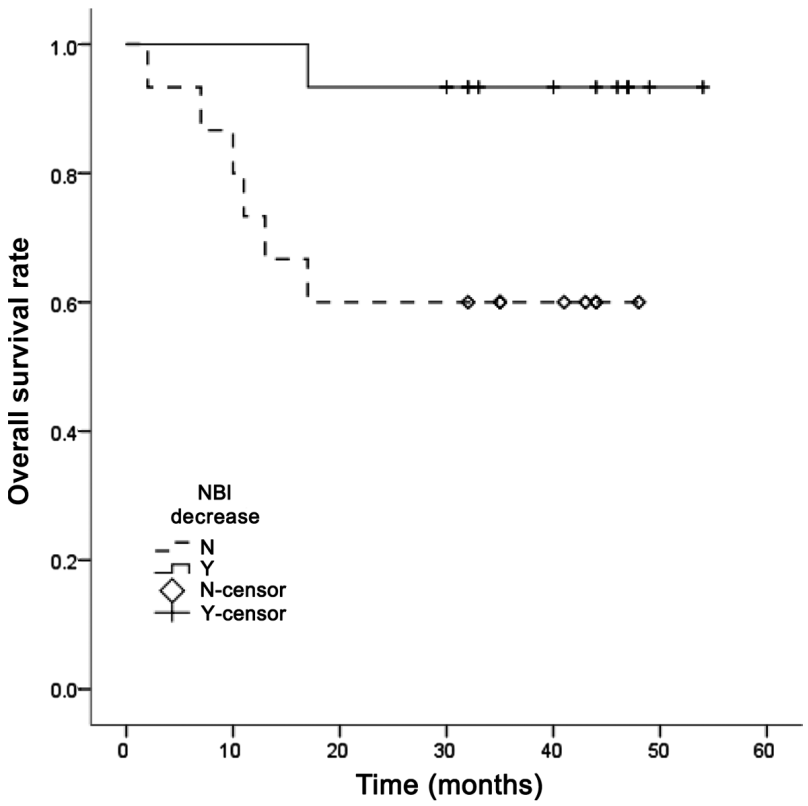

Figure 3. Association between decreased/unchanged NBI blood vessel classification and survival prognosis. NBI, narrowband imaging; N, no; Y, yes

stage of tumor invasion, TGF- $\beta$ expression increases due to its promotive effect on the advanced tumor, but decreases in the middle stage (stage II) of tumor growth (18). In the present study, the majority of patients with decreased NBI vascular type were classified as V-type to IV-type, from the late stage to the middle and late stages. Compared with the unchanged NBI vascular type, the expression of TGF- $\beta$ decreased in the decreased NBI vascular type, which was statistically significant and consistent with the conclusions drawn in a previous study (27).

TGF- $\beta$ has also been indicated to interact with a variety of vascular factors. Dang et al (28) revealed that when TGF- $\beta 1$ was added to scc 9 and myofibroblasts, the expression levels of MMP-3 and MMP-9 were increased. Additionally, the MMP family is an important factor in tumor angiogenesis (29), since it can degrade the extracellular matrix, destroy the structure of the basement membrane and interact with basic FGF, TGF and other cytokines in the process of vascular remodeling (30). This interaction means that the front-end endothelium of neovascularization continues to proliferate, whereas the back-end endothelium forms a close connection and subsequently forms a complete lumen structure to enable blood supply to tumor cells (30). MMP-9 is an important component of MMPs, and as a gelatinase, and it mainly degrades collagen IV (31). Furthermore, it has been indicated that MMP-9 is an important angiogenic factor in promoting the transformation of tumor epithelial stroma (32). According to experimental findings for oral squamous cell carcinoma, TGF- $\beta$ can regulate MMP-9 by enhancing the expression of the transcription factor Snail/ETS proto-oncogene 1, transcription factor (33), and thus promoting the development of oral cancer. Therefore, MMP-9 and other angiogenesis-associated factors may be associated with the transformation of the tumor epithelial stroma. Overexpression of MMP-9 can lead to the exposure of hidden functional sites in the normal state, which is associated with basement membrane degradation, extracellular mechanism remodeling and cell migration, and can accelerate the formation of blood vessels (31). In the present study, MMP-9 expression decreased with decreased NBI blood vessel classification, which also demonstrated that MMP-9 expression was higher in stages IV or V according to the NBI vascular classification. In addition, MMP-9 has been revealed to be associated with the invasion and cervical lymph node metastasis of tongue squamous cell carcinoma exhibiting different invasion modes (34).

Tumor development is also affected by the tumor microenvironment, which can change tumor angiogenesis by regulating the tumor immune microenvironment and releasing cytokines. The inflammatory microenvironment can increase the mutation rate of cells and provide support for tumor initiation $(24,35)$. It has been indicated that the IL family can upregulate MMP-9 expression through the infiltration and recruitment of $\mathrm{Th}$ helper 17 cells to inflammatory cells, thus promoting tumor angiogenesis and serving an important role in the process of tumor invasion and metastasis (36). Other factors, such as IL-6, are involved in the transformation of epithelial stroma, and can influence the occurrence and development of tumors by reacting to alterations in the tumor microenvironment (37). These factors are highly associated with poor patient prognosis and the early recurrence of oropharyngeal squamous cell carcinoma and esophageal squamous cell carcinoma (38). Via the Janus kinase/STAT3 signaling pathway, epithelial-to-mesenchymal transition (EMT) is also mediated, and angiogenesis and lymphangiogenesis are enhanced by VEGF, promoting tumor progression (38). For the IL-1 that was used in the present study, the relevant literature $(8,39)$ indicates that IL-1, together with VEGF and FGF, is associated with tumor angiogenesis and lymphangiogenesis. In addition, studies by Paik et al (40) and Cui et al (41) have revealed that the concentration of IL-6 secreted by fibroblasts is increased 13 times after $24 \mathrm{~h}$ of IL-1 stimulation. IL-1 $\beta$ can promote the production of IL-6 in fibroblasts and promote tumor angiogenesis, metastasis and invasion through EMT, which is induced by IL-6 $(40,41)$. The results of the present study also indicated that IL-1 $\beta$ expression decreased with decreased NBI vascular classification, and increased in the later stage.

I-TAC was also used in the present study. In 1998, the role of the chemokine I-TAC in the migration of chemotactic cells was revealed for the first time (42). Cells were observed to migrate to the source of the chemokine along the signal of increased chemokine concentration (42). Subsequently, it was demonstrated that chemokines, as key signaling molecules in the tumor microenvironment, serve an important role in tumor invasion and metastasis. In terms of angiogenesis, I-TAC can be used as a factor of angiogenesis or anti-angiogenesis, and I-TAC can also interact with VEGF (43). Cancer cells can produce I-TAC directly, or release I-TAC to regulate angiogenesis by regulating the surrounding inflammatory cells (44). I-TAC is a novel tumor microcirculation mode that is different from the classic tumor angiogenesis and does not depend on endothelial cells; however, no significant differential expression of I-TAC was observed in the present study. Therefore, the role of chemokines in the angiogenesis of head and neck squamous cell carcinoma requires further study.

The present study revealed that in patients with hypopharyngeal cancer, changes in NBI vascular classification before and after induction chemotherapy reflected the therapeutic 
effects of chemotherapy and were associated with the prognosis of patients. IL-1 $\beta$, TGF- $\beta$ and MMP-9, as angiogenesis-associated factors, were significantly different in patients with differing NBI vascular classifications, although they were not independent factors of survival prognosis. However, in terms of chemotherapy and pre-treatment of patients, they may serve a role in guiding patient treatment.

It was hypothesized that IL- $1 \beta$, TGF- $\beta$ and MMP-9 can be used as predictors of the effect of induction chemotherapy on poorly differentiated hypopharyngeal carcinoma. Therefore, when patients with advanced hypopharyngeal cancer undergo induction chemotherapy, NBI examination and screening for associated vascular factors should be performed before and after chemotherapy, as changes in vascular classification and abnormal expression of vascular factors can be used as important reference factors. In addition, the lack of quantitative immunohistochemistry analysis may be a limitation of the present study. A more comprehensive understanding of the mechanism of tumor angiogenesis will help to inform the clinical application of anti-angiogenesis. Although a variety of anti-angiogenic drugs combined with chemotherapy have been introduced in clinical applications or have been entered into clinical trials, they do not completely resolve tumor angiogenesis, and the treatment therefore requires further improvement.

\section{Acknowledgements}

Not applicable.

\section{Funding}

Funding was received from the National Natural Science Foundation of China (grant no. 81670946) and The Capital Health Research and Development of Special (grant no. CFH2018-1-2052).

\section{Availability of data and materials}

The datasets used and/or analyzed during the current study are available from the corresponding author on reasonable request.

\section{Authors' contributions}

GY and HD analyzed and interpreted the patient data. WG and HL performed the experiments and WG was a major contributor in writing the manuscript. $\mathrm{ZH}$ designed the study. All authors read and approved the final manuscript.

\section{Ethics approval and consent to participate}

The present study was approved by the Ethics Committee of Beijing Tongren Hospital (Beijing, China; approval no. XMLX201507), and patients provided written informed consent to participate in the present study.

\section{Patient consent for publication}

Not applicable.

\section{Competing interests}

The authors declare that they have no competing interests.

\section{References}

1. Cooper JS, Porter K, Mallin K, Hoffman HT, Weber RS, Ang KK, Gay EG and Langer CJ: National cancer database report on cancer of the head and neck: 10-year update. Head Neck 31: 748-758, 2009.

2. Newman JR, Timothy M Connolly, Illing EA, Kilgore ML, Locher JL and Carroll WR: Survival trends in hypopharyngeal cancer: A population-based review. Laryngoscope 125: 624-629, 2015.

3. Kuo P, Chen MM, Decker RH, Yarbrough WG and Judson BJ: Hypopharyngeal cancer incidence, treatment, and survival: Temporal trends in the United States. Laryngoscope 124: 2064-2069, 2014.

4. Chen P, Yu W, Huang J, Xu H, Li G, Chen X and Huang Z: Matched-pair analysis of survival in patients with poorly differentiated versus well-differentiated glottic squamous cell carcinoma. Oncotarget 8: 14770-14776, 2017.

5. Kang CJ, Lin CY, Wang HM, Fan KH, Ng SH, Lee LY, Chen IH, Huang SF, Liao CT and Yen TC: The number of pathologically positive lymph nodes and pathological tumor depth predicts prognosis in patients with poorly differentiated squamous cell carcinoma of the oral cavity. Int J Radiat Oncol Biol Phys 81: e223-e230, 2011.

6. Pfister DG, Spencer S, Brizel DM, Burtness B, Busse PM, Caudell JJ, Cmelak AJ, Colevas AD, Dunphy F, Eisele DW, et al: Head and neck cancers, Version 2. 2014. Clinical practice guidelines in oncology. J Natl Compr Canc Netw 12: 1454-1487, 2014.

7. Guo W, Yin GF, Huang JW, Yang Z, Liu HF, Zhang Y, Xu HB, Liu ZY and Huang ZG: Effect of vascular changes on prognosis after induced chemotherapy for advanced hypopharyngeal carcinoma. Zhonghua Er Bi Yan Hou Tou Jing Wai Ke Za Zhi 54: 591-596, 2019 (In Chinese).

8. Kasza A: IL-1 and EGF regulate expression of genes important in inflammation and cancer. Cytokine 62: 22-33, 2013.

9. John A and Tuszynski G: The role of matrix metalloproteinases in tumor angiogenesis and tumor metastasis. Pathol Oncol Res 7: 14-23, 2001.

10. Gale N, Poljak M and Zidar N: Update from the 4th edition of the world health organization classification of head and neck tumours: What is new in the 2017 WHO blue book for tumours of the hypopharynx, larynx, trachea and parapharyngeal space. Head Neck Pathol 11: 23-32, 2017.

11. Amin MB: American Joint Committee on Cancer. American Cancer Society. AJCC Cancer Staging Manual. 8th edition. Springer, Chicago, IL, 2017.

12. Ni XG, He S, Xu ZG, Gao L, Lu N, Yuan Z, Lai SQ, Zhang YM, Yi JL, Wang XL, et al: Endoscopic diagnosis of laryngeal cancer and precancerous lesions by narrow band imaging. J Laryngol Otol 125: 288-296, 2011.

13. Engel KB and Moore HM: Effects of preanalytical variables on the detection of proteins by immunohistochemistry in formalin-fixed, paraffin-embedded tissue. Arch Pathol Lab Med 135: 537-543, 2011.

14. Jain RK and Carmeliet P: SnapShot: Tumor angiogenesis. Cell 149: 1408 e1, 2012.

15. Loges S, Clausen H, Reichelt U, Bubenheim M, Erbersdobler A, Schurr P, Yekebas E, Schuch G, Izbicki J, Pantel K, et al: Determination of microvessel density by quantitative real-time PCR in esophageal cancer: Correlation with histologic methods, angiogenic growth factor expression, and lymphnode metastasis. Clin Cancer Res 13: 76-80, 2007.

16. Bach F, Uddin FJ and Burke D: Angiopoietins in malignancy. Eur J Surg Oncol 33: 7-15, 2007.

17. Li LY, Barlow KD and Metheny-Barlow LJ: Angiopoietins and Tie2 in health and disease. Pediatr Endocrinol Rev 2: 399-408, 2005.

18. Wu H: Morphological changes of capillary loops in the epithelial papilla and correlation between vascular growth factors, infiltration related cytokines and superficial esophageal cancer [dissertation]. Shandong University, Shandong, 2017.

19. Tsutsui S, Inoue H, Yasuda K, Suzuki K, Takeuchi H, Nishizaki T, Higashi $\mathrm{H}$, Era S and Mori M: Angiopoietin-2 expression in invasive ductal carcinoma of the breast: Its relationship to the VEGF expression and microvessel density. Breast Cancer Res Treat 98: 261-266, 2006. 
20. Viallard C and Larrivée B: Tumor angiogenesis and vascular normalization: Alternative therapeutic targets. Angiogenesis 20: 409-426, 2017.

21. De Bock K, Cauwenberghs S and Carmeliet P: Vessel abnormalization: Another hallmark of cancer? Molecular mechanisms and therapeutic implications. Curr Opin Genet Dev 21: 73-79, 2011.

22. Bikfalvi A: History and conceptual developments in vascular biology and angiogenesis research: A personal view. Angiogenesis 20: 463-478, 2017.

23. Fujisaka S, Usui I, Ikutani M, Aminuddin A, Takikawa A, Tsuneyama K, Mahmood A, Goda N, Nagai Y, Takatsu K and Tobe K: Adipose tissue hypoxia induces inflammatory M1 polarity of macrophages in an HIF- $1 \alpha$-dependent and HIF-1 $\alpha$-independent manner in obese mice. Diabetologia 56 1403-1412, 2013

24. Falanga V, Zhou L and Yufit T: Low oxygen tension stimulates collagen synthesis and COL1A1 transcription through the action of TGF-beta1. J Cell Physiol 191: 42-50, 2002.

25. Lu SL, Reh D, Li AG, Woods J, Corless CL, Kulesz-Martin M and Wang XJ: Overexpression of transforming growth factor betal in head and neck epithelia results in inflammation, angiogenesis and epithelial hyperproliferation. Cancer Res 64: 4405-4410, 2004

26. Biobe GC, Schiemann WP and Lodish HE: Role of transforming growth factor beta in human disease. N Engl J Med 343: 1350-1358, 2000.

27. Luo J, Chen XQ and Li P: The role of TGF- $\beta$ and its receptors in gastrointestinal cancers. Transl Oncol 12: 475-484, 2019.

28. Dang D, Yang Y, Li X, Atakilit A, Regezi J, Eisele D, Ellis D and Ramos DM: Matrix metalloproteinases and TGFbetal modulate oral tumor cell matrix. Biochem Biophys Res Commun 316 : 937-942, 2004

29. Kumar S, Pan CC, Bloodworth JC, Nixon AB, Theuer C, Hoyt DG and Lee NY: Antibody-directed coupling of endoglin and MMP-14 is a key mechanism for endoglin shedding and deregulation of TGF- $\beta$ signaling. Oncogene 33: 3970-3979, 2014.

30. Arriola BP, Scian R, Comerci DJ, Serantes DR, Vanzulli S, Fossati CA, Giambartolomei GH and Delpino MV: Brucella abortus induces collagen deposition and MMP-9 down modulation in hepatic stellate cells via TGF- $\beta 1$ production. Am J Pathol 183: 1918-1927, 2013.

31. Zhang JT, Sun W, Zhang WZ, Ge CY, Liu ZY, Zhao ZM, Lu XS and Fan YZ: Norcantharidin inhibits tumor growth and vasculogenic mimicry of human gallblad-der carcinomas by suppression of the PI3-K/MMPs/Ln-5 22 signaling pathway. BMC Cancer 14 193,2014

32. Smith A, Teknos TN and Pan Q: Epithelial to mesenchymal transition in head and neck squamous cell carcinoma. Oral Oncol 49 287-292, 2013

33. Sun L, Diamond ME, Ottaviano AJ,Joseph MJ, Ananthanarayan V and Munshi HG: Transforming growth factor-betal promotes matrix metalloproteinase-9-mediated oral cancer invasion through snail expression. Mol Cancer Res 6: 10-20, 2008.
34. Ji H, Gao Z and Feng Z: Expression of matrix metalloproteinase-9 in squamous cell carcinoma of the tongue with different pattern of invasion and clinical significance. J Oral Sci Res 28: 488-490, 2012.

35. Colotta F, Allavena P, Sica A, Garlanda C and Mantovani A: Cancer-related inflammation, the seventh hallmark of cancer: Links to genetic instability. Carcinogenesis 30: 1073-1081, 2009.

36. Hu Y, Lu L, Qiu Z, Huang Q, Chen Y and Chen L: Mechanical stretch aggravates aortic dissection by regulating MAPK pathway and the expression of MMP-9 and inflammation factors. Biomed Pharmacother 108: 1294-1302, 2018.

37. Zhang HY, Zheng XZ, Wang XH, Xuan XY, Wang F and Li SS: S100A4 mediated cell invasion and metastasis of esophageal squamous cell carcinoma via the regulation of MMP-2 and E-cadherin activity. Mol Biol Rep 39: 199-208, 2012.

38. Chang Q, Bournazou E, Sansone P, Berishaj M, Gao SP, Daly L, Wels J, Theilen T, Granitto S, Zhang X, et al: The IL-6/JAK/Stat3 feed-forward loop drives tumorigenesis and metastasis. Neoplasia 15: 848-862, 2013

39. Siveen KS, Prabhu K, Krishnankutty R, Kuttikrishnan S, Tsakou M, Alali FQ, Dermime S, Mohammad RM and Uddin S: Vascular endothelial growth factor (VEGF) signaling in tumour vascularization: Potential and challenges. Curr Vasc Pharmacol 15: 339-351, 2017.

40. Paik JS, Cho WK, Oh EH, Lee SB and Yang SW: Palmitate induced secretion of IL-6 and MCP-1 in orbital fibroblasts derived from patients with thyroid-associated ophthalmopathy. Mol Vis 18: 1467-1477, 2012.

41. Cui G, Yuan A, Sun Z, Zheng W and Pang Z: IL-1//IL-6 network in the tumor microenvironment of human colorectal cancer. Pathol Res Pract 214: 986-992, 2018.

42. Cole KE, Strick CA, Paradis TJ, Ogborne KT, Loetscher M, Gladue RP, Lin W, Boyd JG, Moser B, Wood DE, et al: Interferon-inducible $\mathrm{T}$ cell alpha chemoattractant (I-TAC): A novel non-ELR CXC chemokine with potent activity on activated $\mathrm{T}$ cells through selective high affinity binding to CXCR3. J Exp Med 187: 2009-2021, 1998.

43. Atanackovic D, Cao Y, Kim JW, Brandl S, Thom I, Faltz C, Hildebrandt Y,Bartels K, de Weerth A,Hegewisch-Becker S, et al: The local cytokine and chemokine milieu within malignant effusions. Tumour Biol 29: 93-104, 2008.

44. Vlahakis SR, Villasis-Keever A, Gomez TS, Bren GD and Paya CV: Human immunodeficiency virus-induced apoptosis of human hepatocytes via CXCR4. J Infect Dis 188: 1455-1460, 2003.

This work is licensed under a Creative Commons Attribution-NonCommercial-NoDerivatives 4.0 International (CC BY-NC-ND 4.0) License. 